\title{
MT-data analysis from a survey in the Mygdonia basin (N. Greece)
}

\author{
John P. Makris $\left({ }^{1}\right)$, Alexandros S. Savvaidis $\left({ }^{2}\right)$ and Filippos Vallianatos $\left({ }^{1}\right)$ \\ ( $\left.{ }^{1}\right)$ Department of Electronics, Technological Educational Institute of Crete, Chalepa, Chania, \\ Crete Island, Greece \\ ${ }^{2}{ }^{2}$ Laboratory of Geophysics, Department of Geology, Aristotle University of Thessaloniki, Greece
}

\begin{abstract}
A magnetotelluric (MT) profile comprising eight measuring sites was conducted in the Mygdonia basin, a European Seismological Test Site. The MT-stations were deployed in a direction almost perpendicular to the major axis of the sedimentary basin to cover the area between the Lagada and Volvi lakes. The earth beneath the measuring points was considered to consist of a 2D-regional basement coupled with local, near surface, 3D-inhomogeneities. Impedance tensor decomposition analysis in conjunction with the magnetotelluric study of Mohr circles was implemented in the MT-data. From the electric field polarization diagrams and the interpretation of the Mohr circles results, it is inferred that the local structure at all the sites polarizes the electric field in comparable directions ranging from $\mathrm{N} 60^{\circ} \mathrm{E}$ to $\mathrm{N} 80^{\circ} \mathrm{E}$, except for the cases of the two stations located at the northern and southern borders of the basin, where the boundary conditions produce a deviation. Furthermore, the deeper structure seems to be two-dimensional. The strike-direction of the $2 \mathrm{D}$-basement was found to be $\sim \mathrm{N} 70^{\circ} \mathrm{E}$. Although the regional geological strike in the area is NW-SE, the regional geoelectric strike is more compatible with the orientation of the faults in the area.
\end{abstract}

Key words magnetotelluric-tensor decomposition Mohr circles - Mygdonia basin - Greece

\section{Introduction}

In October 1995, eight magnetotelluric (MT) soundings were carried out in the Mygdonia basin, a European Seismological Test Site (EuroSeisTest, 1995). They were arranged on a $6 \mathrm{~km}$ long profile with a spacing of about $1 \mathrm{~km}$ (fig. 1). The frequency range was $128-0.004 \mathrm{~Hz}$

Mailing address: Dr. Filippos Vallianatos, Technological Educational Institute of Crete, Department of Natural Resources Engineering, Laboratory of Geophysics and Natural Hazards, 3 Romanou St., Chalepa, GR-73133 Chania, Crete Island, Greece; e-mail: fvallian@ chania.teiher.gr and nine channels were employed for each sounding. Five of them served as base station, namely $E_{x}, E_{y}, H_{x}, H_{y}, H_{z}$, and four as reference station, named $E_{x}^{r}, E_{y}^{r}, H_{x}^{r}, H_{y}^{r}$. The data were collected in eight frequency bands using different sampling rates. The last three low frequency bands overlap. The MT-measurements were conducted with the SPAM MkIII instrument (Dawes, 1990), developed at the University of Edinburgh. An up-to-date summary on the instrument used can be found in Ritter et al. (1998).

The area of study is located in Central Macedonia (fig. 1) and occupies the inner of the Hellenic mountain belt, including the Serbomacedonian massif $(\mathrm{Sm})$ to the east and the Circum Rhodope Belt (CRB) to the west (Kauffman et al., 1976). The rocks of these zones consist of the Pre-Alpine and Alpine basement of the area that has a NW-SE strike similar to 


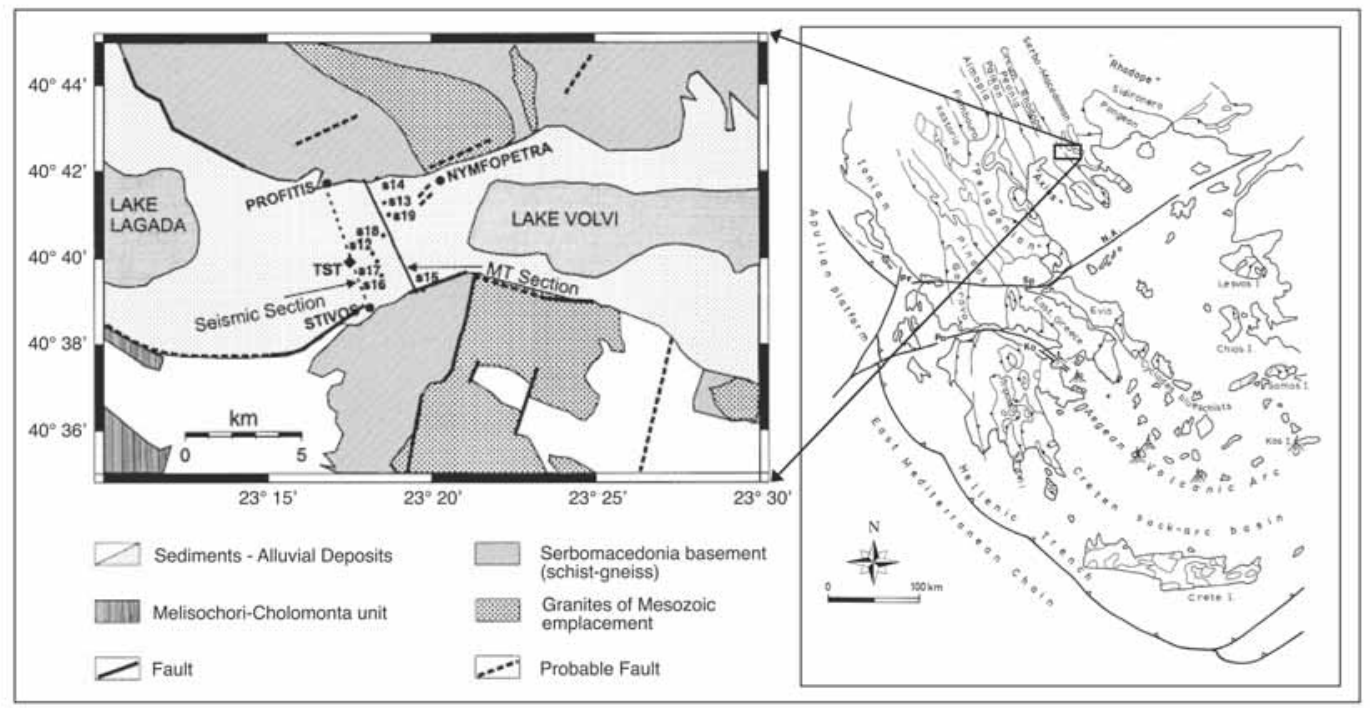

Fig. 1. Rough geotectonic map of Mygdonia basin (the area between the lakes Lagada and Volvi). The numbers shown identify the MT-sites of the survey. The bold line represents a theoretical MT-section onto which the actual locations of the measuring points are projected. The diamond sign (TST) indicates the position of the borehole and the dashed line denotes the seismic profile (Jongmans et al., 1998). The right part of the figure is a simplified geotectonic map of Greece and the continuous line box encloses the area of this study.

the general «Dinaric direction» of the Hellenic mountain belt. Upon these rocks were deposited post-alpine sediments with alluvial deposits after a geotectonic event during Neogene and Quaternary on which a series of graben with E-W to NW-SE trends were formed by normal faulting (Premygdonia basin). At the end of Early Pleistocene, a new tectonic action faulted the Premygdonia basin and a new graben of an E-W direction was framed, forming the Mygdonia Lake. The present lakes Volvi and Lagada are the remnants of the Mygdonia Lake.

In previous works (Savvaidis, 1998; Savvaidis et al., 2000), the electromagnetic response of the sub-surface hemi-space is considered as unified and the impedance tensor is not decomposed. From the MT-polar diagrams of the impedance tensor elements a strike-direction pointing $\mathrm{N} 65^{\circ} \mathrm{E}$ was determined; the inspection of the dimensionality indices calculated (skew, ellipticity) indicated that they are compatible with a 2D-structure, although the skew values for frequencies above $1 \mathrm{~Hz}$ indicated a departure from this high order symmetry and the apparent resistivity curves for higher frequencies are not similar in all stations. The latter result is an indication for the presence of local near-surface inhomogeneities (Vallianatos, 1995; Makris et al., 1997).

The main objective of this work is to present a multi-station extended magnetotelluric study of this area by means of the decomposition of the measured impedance tensor and the MT-representation of Mohr circles.

\section{Impedance tensor decomposition}

Small-scale, near-surface 3D-inhomogeneities act as semi-static scatterers of the regional electric field then the conventional MT-procedure fails to determine the correct principal impedances and the principal induction axes. In such a case, a decomposition of the measured impedance tensor 
may conduce to separate, if possible, local distortion parameters and regional 2D-parameters (Bahr, 1988, 1991; Groom, 1988; Groom and Bailey, 1989; Groom and Bahr, 1992; Groom et al., 1993; Chave and Smith, 1994). Consider a 2D-regional geoelectric structure, where

$$
\vec{Z}_{2 \mathrm{D}}=\left(\begin{array}{cc}
0 & \alpha \\
-b & 0
\end{array}\right)
$$

the impedance tensor that refers to its principal coordinate system. The scattering of the electric field by local inhomogeneities can be described by an impedance tensor in the following form:

$$
\begin{gathered}
\vec{Z}_{m}=\left(\begin{array}{ll}
C_{1} & C_{2} \\
C_{3} & C_{4}
\end{array}\right)\left(\begin{array}{cc}
0 & \alpha \\
-b & 0
\end{array}\right)= \\
=\left(\begin{array}{ll}
-C_{2} b & C_{1} \alpha \\
-C_{4} b & C_{3} \alpha
\end{array}\right)
\end{gathered}
$$

where the distortion tensor $\overleftrightarrow{C}$ is real and frequency independent (at low frequencies) [superimposition model, 3D(local)/2D(regional)]. Thus, in the principal axes system (and not in an arbitrary measuring coordinate system) the elements in each column of $\overleftrightarrow{Z}_{m}$ should have the same phase. A set of parameters is defined (Bahr, 1988, 1991). The rotationally invariant scalar parameter, $\eta$, termed as the regional skew, which is a measure of lack of symmetry (if $\eta>0.3$ then the regional structure is 3D), the rotationally invariant parameter, $\mu$, which is a measure of the phase difference (thus an indicator of a regional 1Dstructure), the conventional skew index, $s$, which in case of presence of distorting bodies or structures, depends only on the distortion tensor real elements

$$
s \equiv \frac{\left|Z_{x x}+Z_{y y}\right|}{\left|Z_{x y}-Z_{y x}\right|}=\frac{\left|C_{3}-C_{2}\right|}{\left|C_{1}+C_{4}\right|}
$$

The ratio $\xi=\eta / s$ represents the relative contribution of the local distortion to $s$, i.e. if $\xi<<1$ then $s$ is totally determined by this distortion.
By introducing the complex «telluric vectors» in the measuring coordinate frame (Bahr, 1988, 1991)

$$
\vec{e}_{x}=Z_{x x} \hat{x}+Z_{y x} \hat{y}
$$

and

$$
\vec{e}_{y}=Z_{x y} \hat{x}+Z_{y y} \hat{y}
$$

where $(x \rightarrow$ NS, $y \rightarrow$ EW), two angular deviations of the telluric vectors $\vec{e}_{x}$ and $\vec{e}_{y}$ are determined in the coordinate frame of the regional geoelectric structure

$\tan \left(\beta_{1}\right)=-C_{2} / C_{4}$ and $\tan \left(\beta_{2}\right)=C_{3} / C_{1}$

hereafter termed «skew angles». In cases where the local inhomogeneities produce strong local channeling of the regionally induced electric currents, it is expected $\left|\beta_{2}-\beta_{1}\right| \approx 90^{\circ}$.

Furthermore, the decomposition procedure suggested by Groom and Bailey (Groom, 1988; Groom and Bailey, 1988, 1989, 1991; Groom et al., 1993) proceeds to decomposition also of the distortion tensor

$$
\begin{gathered}
\vec{C}=g N_{t}\left(\begin{array}{cc}
1 & -t \\
t & 1
\end{array}\right) N_{e}\left(\begin{array}{ll}
1 & e \\
e & 1
\end{array}\right) N_{s}\left(\begin{array}{cc}
1+s & 0 \\
0 & 1-s
\end{array}\right)= \\
=\frac{g}{\sqrt{\left(1+t^{2}\right)\left(1+e^{2}\right)\left(1+s^{2}\right)}} \cdot \\
\cdot\left(\begin{array}{ll}
(1+s)(1-t e) & (1-s)(e-t) \\
(1+s)(e+t) & (1-s)(1+t e)
\end{array}\right)
\end{gathered}
$$

where $\overleftrightarrow{T}$ is the twist distortion tensor, $\overleftrightarrow{S}$ is the shear distortion tensor, $\overleftrightarrow{A}$ is the anisotropy distortion tensor, $N_{i}$ are normalizing factors and $g$ a real scalar characterizing the measuring site. Then the measured impedance tensor is described 
by the equation

$$
\begin{gathered}
\vec{Z}_{m}=\hat{R} g \vec{T} \vec{S} \vec{A} \vec{Z}_{2 \mathrm{D}} \hat{R}^{t}=\hat{R} \vec{T} \vec{Z}_{2 \mathrm{D}}^{\prime} \hat{R}^{t} \\
\text { with } \vec{Z}_{2 \mathrm{D}}^{\prime}=g\left(\begin{array}{cc}
0 & (1+s) \cdot \alpha \\
-(1-s) \cdot b & 0
\end{array}\right)
\end{gathered}
$$

where $\hat{R}$ is the operator for the clockwise rotation of the measuring coordinate system, in order to coincide with the principal axes of the 2D-structure. The Groom et al. (1993) methodology successfully determines the dimensionality of the dominant structure and recovers the regional impedance responses (in case, of course, where the regional structure can be characterized approximately as 1D or 2D). In addition, the principal directions of the regional induction are determined but with the ambiguity concerning the strike-direction. In cases of strong local channeling, for the shear-distortion parameter holds: $|e| \approx 1$.

The decomposition analyses, introduced by Bahr and Groom and Bailey, were implemented
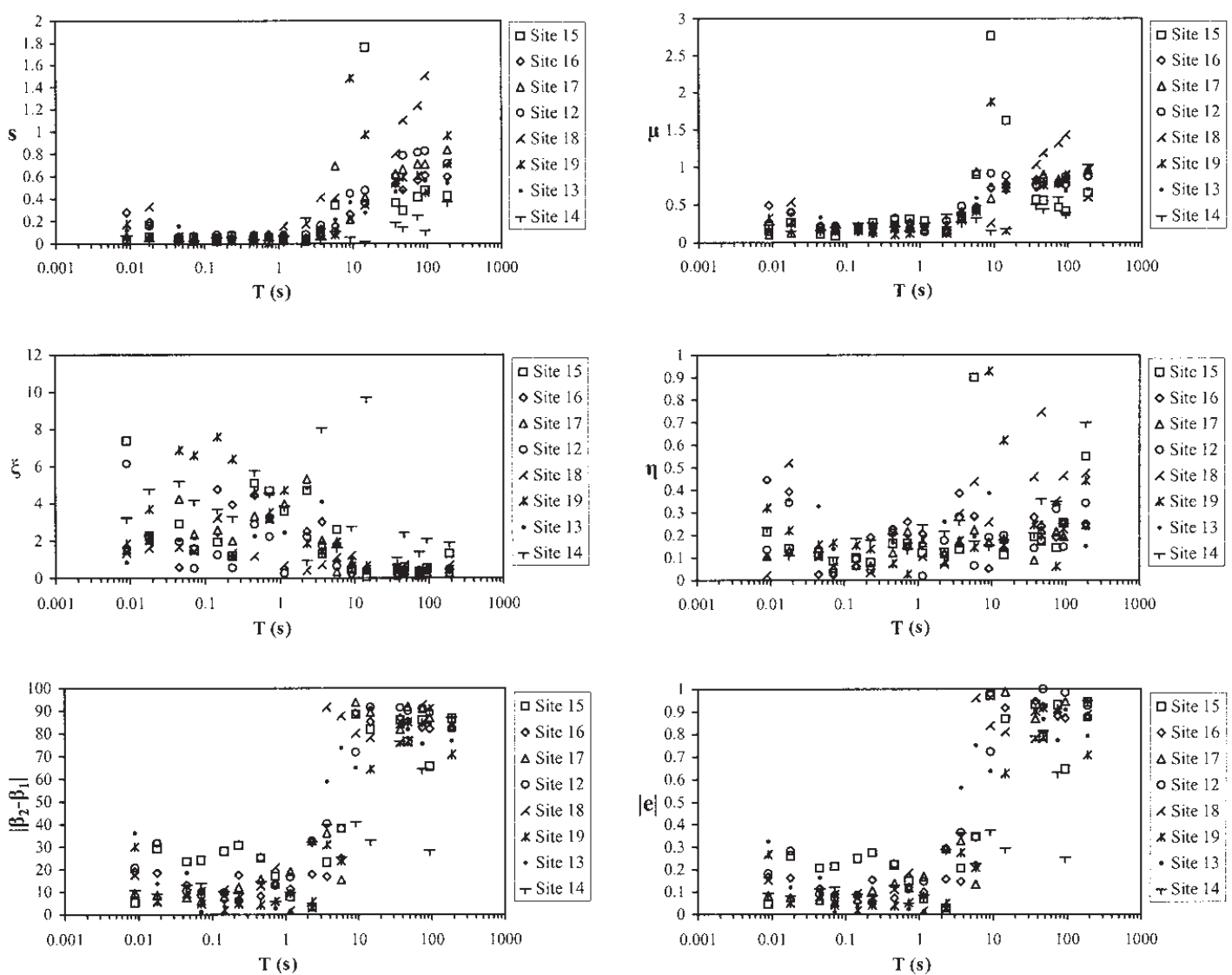

Fig. 2. Dimensional and distortion parameters versus period determined by impedance tensor decomposition analyses (Bahr, Groom and Bailey) of the MT-data from all the sites of the MT-survey. 

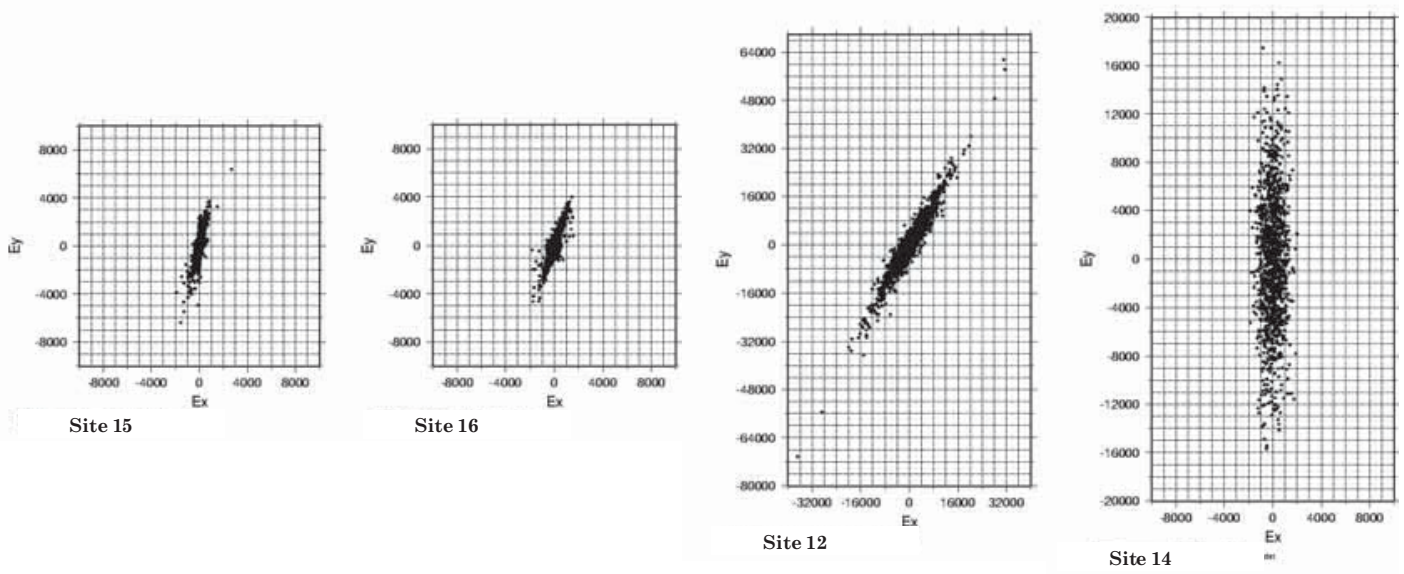

Fig. 3. Observed polarization diagrams of the electric field measured at the sites 15, 16, 12 and 14 of Mygdonia MT-profile. At each diagram, the gradient of the trend-line corresponds to the local polarization angle (deviating clockwise from NS-direction) of the electric field at the respective site. This calculation was done for all the measuring sites.

in the MT-data collected at the eight measuring sites of the MT-survey (fig. 1). From the interpretation of the results (fig. 2) the following conclusions are drawn: i) the model of the geoelectric structure that better fits the low frequency MT-data is 2D-(regional)/3D(local). A constrained study of the high frequency data $(e . g ., \geq 0.1 \mathrm{~Hz})$ concludes that Cagniard (1953) and Swift (1967) models of a $1 \mathrm{D}$ and 2D-conductivity distribution are valid (skew parameter, $s$, very small, see fig. 2). By combining them with models obtained by gravity-data (Savvaidis, 1998; Savvaidis et al., 2000) and seismic soundings (Jongmans et al., 1998) and information gained from a borehole at the position TST (fig. 1), the upper geoelectrical layers and geological formations were successfully resolved (Savvaidis, 1998; Savvaidis et al., 2000). ii) The regional principal axes found to deviate from the measuring coordinate axes $(x \rightarrow \mathrm{NS}, y \rightarrow \mathrm{EW}) \sim$ $70^{\circ}$ clockwise. iii) Moderate twist distortion $(|t|<1)$ of the regionally induced electric field is present at all the sites of the MT-profile. iv) Strong shear distortion (local channeling) of the regionally induced electric field is a remarkable characteristic of the area (common at all the sites) due to the facts that the relevant shear-parameter, $e$, is close to unity and the skew angle addition, $\beta_{2}-\beta_{1}$, found to be $\sim 90^{\circ}$ for periods greater than $9 \mathrm{~s}$ and for all the measuring sites (fig. 2). The latter results indicate that the measured electric field is linearly polarized. We draw the attention of the reader to the fact that this was independently verified by the observed polarization diagrams (fig. 3), which exhibit directional angles (local strikes) of the local channeling diversified from site to site (this is more evident for the cases of the two sites located at the northern and southern borders of the basin, due to geological conditions at its boundaries). This implies that the area under study is inhomogeneous.

\section{Mohr circles analysis}

Mohr circles are commonly met in the analysis of mechanical stress but they can be used similarly to depict magnetotelluric impedance tensor information and to determine 
the characteristic strike-directions in local and/or regional scale (Lilley et al., 1989; Lilley, 1993a,b; Makris, 1997; Makris et al., 1997, 1999). Figure 4 depicts, for various frequencies, the Mohr circles $Z_{x x}^{\prime}(\vartheta)$ versus $Z_{x y}^{\prime}(\vartheta)$ - solid line circle groups - constructed separately for the real and imaginary parts, for site 12 of Mygdonia basin (similar diagrams were constructed for the rest of the sites of the MT-survey). Especially for the low frequency range $(e . g ., \leq 0.1 \mathrm{~Hz})$, these circles pass very close to or approximately through the origin for all the measuring sites and independently of the consideration of either the real or the imaginary parts of the impedance tensor elements. This result implies that irrespectively of the polarization of the incident magnetic field, the electric field is linearly polarized in the direction of the $y^{\prime}\left(\vartheta_{l}\right)$-axis. The directional angles (local strikes) obtained by this analysis (fig. 5) are in agreement with the gradients of the trend-lines of the relevant observed electric field polarization diagrams for each site (fig. 3 ).

A conjugate form of the aforementioned Mohr circles was introduced by Makris (Makris, 1997; Makris et al., 1997, 1999). The relevant Mohr circles for site 12 are also depicted in fig. 4 (dashed-line circle groups). They exhibit the same characteristics, i.e. again they pass very close to or approximately through the origin for all the measuring sites and independently of the consideration of either the real or the imaginary parts. This result refers to the $H$-polarization mode of an ideal 2D-regional geoelectric structure (e.g., a vertical boundary), if the measuring site lies on the conductive medium but close to the

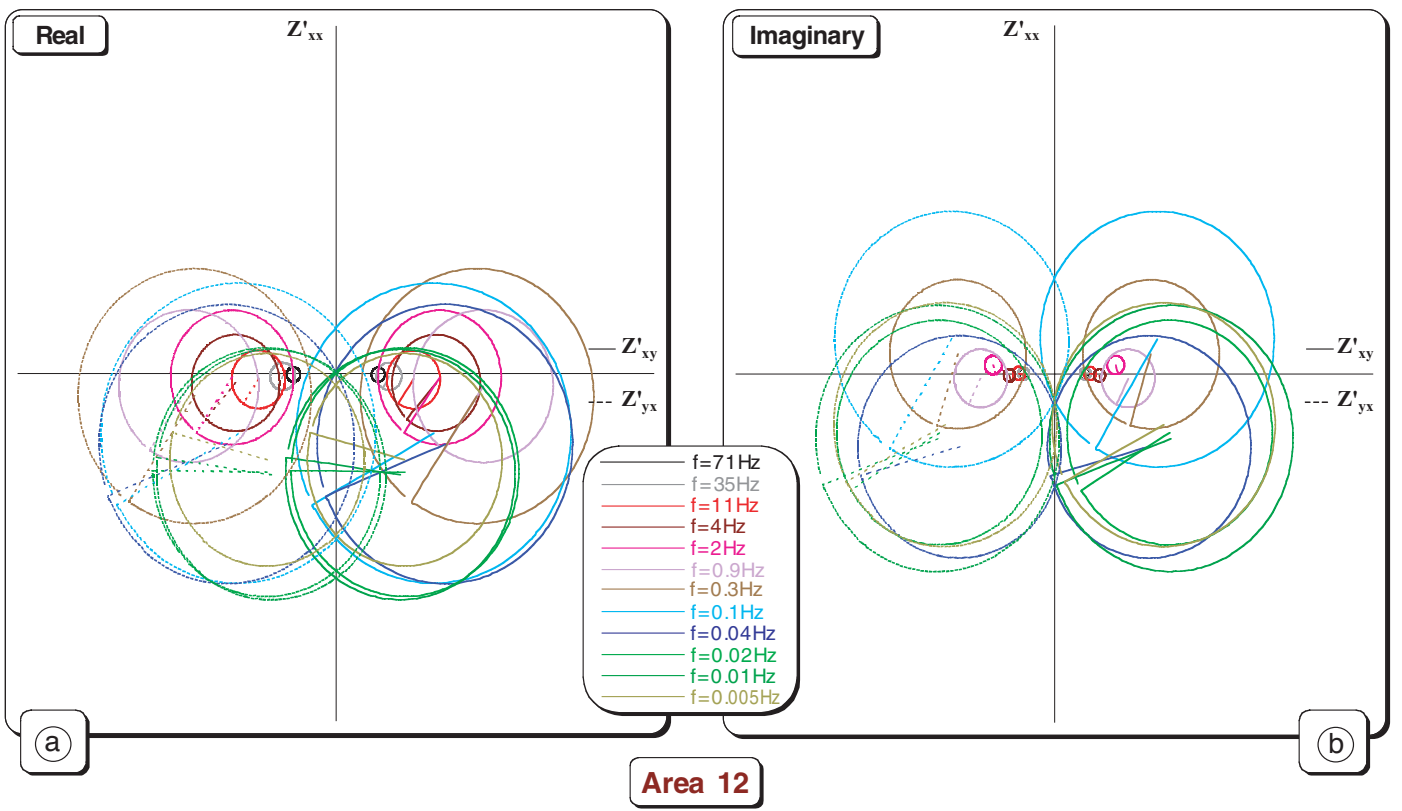

Fig. 4a,b. Mohr-circles for various periods, by taking (a) the real and (b) the imaginary parts respectively of the $\mathrm{Z}^{\prime}$ and $\mathrm{Z}^{\prime}$ impedance tensor elements [left swarm of circles at diagrams (a) and (b)] and of the $Z^{\prime}$ and $Z^{\prime}$ impedance tensor elements [right swarm of circles at diagrams (a) and (b)], constructed using the MT-data from site 12 of Mygdonia area. [cf., a line connects the center with the respective first point (which corresponds to a rotation angle equal to $0^{\circ}$ ) of each circle. Also, the last two points, which correspond to the rotation angles $179^{\circ}$ and $180^{\circ}$ respectively, are intentionally omitted in order to depict the counterclockwise way of circle construction]. 
MT-data analysis from a survey in the Mygdonia basin (N. Greece)
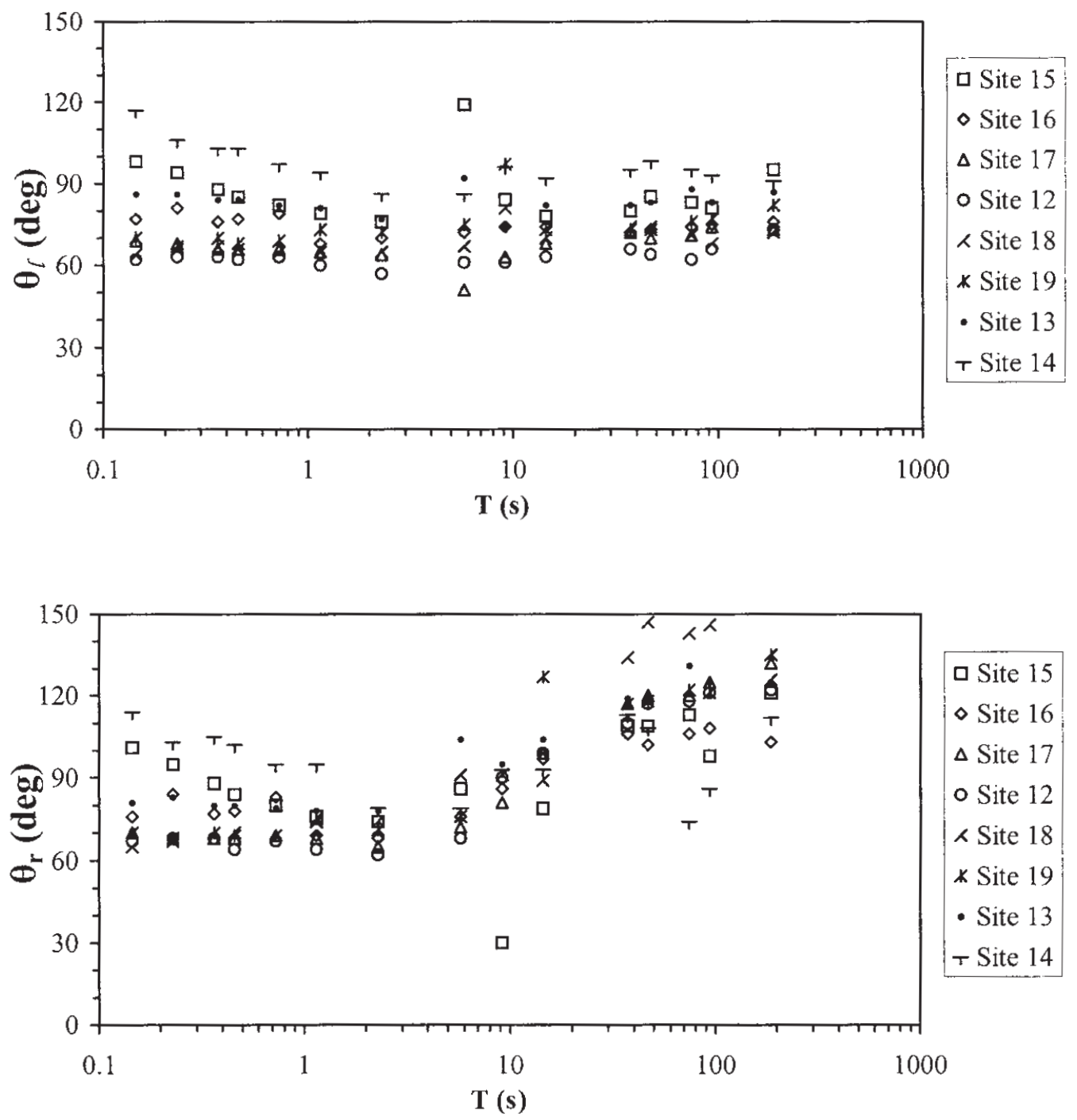

Fig. 5. Directional angles (clockwise from NS-direction) of local strike, $\theta_{1}$ and regional strike, $\theta_{r}$ versus period. They were determined from the Mohr-circles, which have been constructed using the MT-data (by considering the real parts of the impedance tensor elements) for each one of the sites of the Mygdonia basin survey.

resistivity contrast (Fischer et al., 1992). The directional angle (regional strike) was found to be approximately $\mathrm{N} 70^{\circ} \mathrm{E}$, at all the measuring sites for periods above $0.1 \mathrm{~s}$, but for periods higher than $3 \mathrm{~s}$ it deviates clockwise tending to coincide with the dominant geological strike, i.e. $\sim \mathrm{N} 120^{\circ} \mathrm{E}$ (fig. 5).

\section{Discussion}

In this work, the impedance tensors, measured at all the sites of the MT-survey, were decomposed using Bahr's and Groom's and Bailey's procedures, which consider the model of a regional 2D-structure where $3 \mathrm{D}$, 
or 2D-inhomogeneities are embedded (superimposition model).

The study of the dimensionality parameter $\mu$ indicated that the regional structure could not be characterized as $1 \mathrm{D}(\mu>0.1$ throughout the investigated frequency range and for all the measuring sites). The regional skew, $\eta$ (a measure of the departure of the MT-data from the superimposition model) has values: $0.05<$ $\eta<0.3$ for almost all periods, thus indicating that such a model is appropriate to fit the MTdata from all the sites.

Furthermore, the decomposition analysis indicated the existence of an inhomogeneous structure that produces strong channeling for periods equal to or greater than $9 \mathrm{~s}$. The latter was confirmed from the observed electric field polarization diagrams that exhibit linear polarization. The scalar parameter $\xi$ obtains for these periods very small values and this result suggests that the conventional skew, $s$, is totally determined by the distorting structure.

The principal axis system of the underlying regional $2 \mathrm{D}$-structure found to deviate from the measuring coordinate system $(x \rightarrow \mathrm{NS}, y \rightarrow \mathrm{EW})$ by approximately $70^{\circ}$ clockwise.

The MT-study of Mygdonia basin based on the magnetotelluric representation of Mohr circles provided an independent verification of the aforementioned results and resolved the ambiguity concerning the strike-direction of the $2 \mathrm{D}$-structure. The results were obtained mainly from the real parts because the experimental error was much smaller. From the conventional Mohr circles resulted the local strike direction at each site ranging from $\mathrm{N} 60^{\circ} \mathrm{E}$ to $\mathrm{N} 80^{\circ} \mathrm{E}$, except for the cases of the two sites located at the northern and southern borders of the basin, where the boundary conditions produce a deviation.

From the conjugate Mohr circles, the regional strike direction for all the sites was found to be $\mathrm{N} 70^{\circ} \mathrm{E} \pm 10^{\circ}$. It is underscored that although the regional geological strike points NW-SE, the regional geoelectric strike is more compatible with the orientation of the faults in the area. At all the measuring sites and for periods higher than $3 \mathrm{~s}$, the regional geoelectric strike deviates clockwise tending to coincide with the dominant geological strike.

\section{REFERENCES}

BAHR, K. (1988): Interpretation of the magnetotelluric impedance tensor: regional induction and local telluric distortion, J. Geophys., 62, 119-127.

BAHR, K. (1991): Geological noise in magnetotelluric data: a classification of distortion types, Phys. Earth. Planet. Inter, 66, 24-38.

CAGNIARD, L. (1953): Basic theory of the magnetotelluric method of geophysical prospecting, Geophysics, 18, 605-635.

Chave, A.D. and J.T. SMITH (1994): On the electric and magnetic galvanic distortion tensor decompositions, J. Geophys. Res., 99 (B3), 4669-4682.

DAWES, G.J.K. (1990): Feasibility study for a transputerbased upgrade of the Short-Period Automatic Magnetotelluric (SPAM) system, University of Edinburgh, $N E R C$ report $F 3 / G 6 / S 43$.

EUROSEISTEST (1995): Volvi-Thessaloniki: a European test site for engineering seismology, earthquake engineering and seismology, Final Scientific Report.

FisHeR, G., L. SZARKA, A. ADAM and J.T. WEAVER (1992): The magnetotelluric phase over 2D-structures, Geophys. J. Int., 108, 778-786.

GroOM, R.W. (1988): The effects of inhomogeneities on magnetotellurics, Ph.D. Thesis, University of Toronto, Canada.

GROOM, R.W. and R.C. BAILEY (1989): Decomposition of magnetotelluric impedance tensors in the presence of local three-dimensional galvanic distortion, J. Geophys. Res., 94, 1913-1925.

GROOM, R.W. and K. BAHR (1992): Corrections for near surface effects: decomposition of magnetotelluric impedance tensor and scaling corrections for regional resistivities: a tutorial, Surv. Geophys., 13, 341-379.

Groom, R.W., D.R. KURTZ, G.A. JONES and E.D. BoEMER (1993): A quantitative methodology to extract regional magnetotelluric impedances and determine the dimension of the conductivity structure, Geophys. J. Int., 115, 1095-1118.

Jongmans, D., K. Pitalakis, D. DEMANET, D. RAPTAKIS,C. HORRENT, G. TSOKAS, K. LONTZETIDIS and J. RIEPL (1998): EUROSEISTEST: Determination of the geological structure of the Volvi Graben and validation of the basin response to one earthquake and one shot, Bull. Seismol. Soc., 2 (1), 3-14.

KAUFFMAN, G., F. KoCKEL and H. MOLlat (1976): Notes on the stratigraphic and paleogeographic position of the Svoula-formation in the innermost zone of the Hellenides (Northern Greece), Bull. Soc. Geol. Fr., 18, 225-230.

LILLEY, T. (1993a): Magnetotelluric analysis using Mohr circles, Geophysics, 58, 1498-1506.

Lilley, T. (1993b): Mohr circles in magnetotelluric interpretation (i) simple static shift (ii) Bahr's analysis, J. Geomagn. Geoelectr., 45, 833-839.

LILlEY, T., J.H. FILlOUX, I.J. FERGUSON, N.L. BINDOFF and P.J. MulheARN (1989): The Tasman project of seafloor magnetotelluric exploration: experiment and observations, Phys. Earth Planet. Int., 53, 405-421.

MAKRIS, J. (1997): Electromagnetic study of an area sensitive 
to the detection of pre-seismic electrical signals, Ph.D. Thesis, Dept. of Physics, University of Athens, Greece.

MAKRIS, J., N. Bogris and K. EFtaxias (1997): Geoelectric structure of the VAN-station at Ioannina sensitive to the detection of Seismic Electric Signals (SES), Proc. of Athens Academy, 72, 303-421.

MAKRIS, J., N. BogRIS and K. EFTAXIAS (1999): A new approach in the determination of characteristic directions of the geoelectric structure using Mohr circles, Earth Planets Space, 51, 1059-1065.

RitTer, O., A. Junge and J.K. DAwes (1998): New equipment and processing for magnetotelluric remote reference observations, Geophys. J. Int., 132, 535-548.

SAVVAIDIS, A.S. (1998): Geophysical study of the northwestern part of Chalkidiki Peninsula, Ph.D. Thesis, Dept. of Geology, Aristotle University of Thessaloniki, Greece.

Savvaidis, A.S., L.B. Pedersen, G.N. Tsokas and G.J. DAWES (2000): Structure of the Mygdonia basin (N.Greece) inferred from MT and gravity data, Tectonophysics, 317, 171-186.

SWIFT, M.C. Jr. (1967): A magnetotelluric investigation of an electrical conductivity anomaly in the Southwestern United States, Ph.D. Thesis, Mass. Inst. of Tech., MA., U.S.A.

VALLIANATOS, F. (1995): Galvanic distortion of the MTimpedance tensor: application to Ioannina VANstation (Greece), Acta Geophys. Pol., 42 (2), p. 115. 